\title{
DESENVOLVIMENTO DE MODELO PARA MONITORAMENTO E ALARME DA QUEDA DE TEMPERATURA DURANTE O LINGOTAMENTO*
}

\author{
Carlos Alberto Perim 1 \\ Vinicius Thiago Lecco Rampinelli ${ }^{2}$ \\ José Eduardo Pereira ${ }^{3}$
}

\section{Resumo}

Durante o lingotamento contínuo de placas de aço, muitas vezes ocorre uma queda acentuada de temperatura ao longo do processo. Fatores como o tempo de lingotamento, o superaquecimento inicial da panela de aço, a presença de cascão na panela, entre outros, podem alterar significativamente a taxa de queda de temperatura, levando muitas vezes à interrupção prematura do lingotamento. Neste trabalho, será mostrado o desenvolvimento de um modelo de predição de temperatura ao final do lingotamento de uma panela de aço. Este modelo permite antecipar, com razoável nível de incerteza, a temperatura final do aço no distribuidor durante trocas de panela, de forma que forneça subsídios para a tomada de decisão sobre a interrupção do lingotamento, ou a antecipação de abertura de panela com retorno de aço. Desta forma, o índice de trabalho das Máquinas de Lingotamento Contínuo (MLC's) da ArcelorMittal Aços Planos América do Sul seria maximizado, e com possível melhoria no Rendimento de Aço. O modelo se encontra em fase de implantação e validação na MLC\#3, onde foram definidos parâmetros com critérios de decisão de interrupção/antecipação de troca de panela.

Palavras-chave: Lingotamento; Temperatura; Castemp; Modelo de regressão.

\section{DEVELOPMENT OF MODEL TO MONITOR AND ALARMING IN CASE OF LOW TEMPERATURE DURING CASTING}

\section{Abstract}

During continuous casting, sometimes it is observed a deep drop in the steel temperature at the end of casting, which is affected by a series of process parameters. This drop can result in casting interruption, due to freezing inside the nozzle system, between tundish and mold. Aiming prevention of casting interruption, it was proposed the development of a model to estimate the final temperature of a casted heat, in order to provide subsidies for decision-making of stopping or not the casting. This model has already deployed in CCM\#3. It is being evaluated their performance as a function of the predetermined temperature prediction parameters.

Keywords: Continuous casting; Steel freezing.

1 Metallurgical Engineer, M. Sc., Research and Development Specialist of ArcelorMittal, Vitória, ES, Brasil.

2 Control and Automation Engineer, M.Sc., Automation Specialist at ArcelorMittal Tubarão, Vitória, ES, Brasil.

3 Metallurgical Engineer, Steelmaking Process Engineer at ArcelorMittal Tubarão, Vitória, ES, Brasil. 


\section{INTRODUÇÃO}

Obstrução é o processo de bloqueio do fluxo de aço líquido durante a alimentação do molde no lingotamento contínuo. Como resultado da obstrução, ocorre uma diminuição deste fluxo, ou mesmo sua interrupção [1]. A interrupção do fluxo de aço líquido acarreta no encerramento da sequência de lingotamento, impactando diretamente na produtividade da aciaria, na manutenção do sincronismo da aciaria e acarretando aumento do custo de produção com a perda do conjunto refratário.

De forma geral, Thomas descreve quatro diferentes tipos e origem de obstruções [2]. $\mathrm{Na}$ prática, elas resultam da combinação de um ou mais dos tipos identificados. Este trabalho se refere às obstruções causadas pela queda de temperatura do aço líquido no distribuidor, quando atinge valores próximos à sua temperatura liquidus. Esta queda está associada às condições de isolamento térmico, como espessura e tipo do refratário do distribuidor; uso de pós de cobertura e de tampa no distribuidor; volume, fluxo e tempo de residência do aço líquido no distribuidor; e a temperatura do aço líquido vindo da panela de aço. Já a temperatura do aço líquido que abastece o distribuidor depende das condições térmicas da panela de aço, tais como: encharque dos refratários, tempo de aquecimento do aço líquido, uso de tampa de panela, volume de escória, vazão de aço, etc. O controle desses parâmetros é fundamental para a continuidade do processo de lingotamento do aço $[3,4]$.

$\mathrm{O}$ aço líquido no distribuidor deve apresentar um sobreaquecimento em relação a sua temperatura liquidus. Se por um lado, o baixo sobreaquecimento pode acarretar na obstrução dos veios, por outro, o sobreaquecimento exagerado acarreta no aumento do consumo de energia e insumos relacionados ao aquecimento no refino secundário; no aumento do desgaste dos refratários do distribuidor e conjunto de válvulas; além de aumentar o risco de rompimento de pele de aço [3,4].

A ArcelorMittal Tubarão desenvolveu um projeto intitulado "Controle Térmico da Aciaria" afim de otimizar o processo de aquecimento alumino-térmico no refino secundário e reduzir a perda de produtividade do lingotamento contínuo associada à temperaturas elevadas no distribuidor. Segundo os autores, o estado térmico das panelas é a variável mais complexa no controle térmico da aciaria. O estado térmico das panelas está diretamente associado ao tempo em que a panela ficou vazia sem aço, e ao uso de tampa na panela durante este período, conforme mostra a Figura 1. Estes fatores influenciam diretamente na queda de temperatura do aço líquido [3].

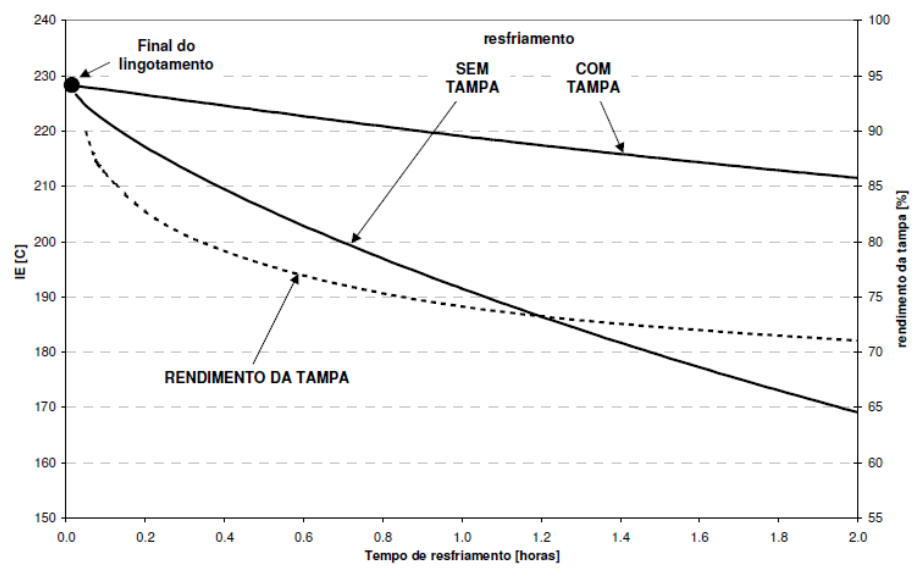

Figura 1. Comparativo da perda térmica da panela de aço com e sem tampa após o lingotamento [3].

Outros estudos [4,5] sobre o comportamento térmico das panelas de Aciaria mostraram que a perda térmica do aço líquido está diretamente relacionada à gestão 
do ciclo de panelas. Durante as etapas do ciclo operacional, o uso de tampa na panela diminui a taxa de queda de temperatura. E ainda que, quanto maior o tempo de ciclo da panela, ou tempo de espera de vazamento, maior será a perda térmica do aço líquido na panela. A Figura 2 apresenta a relação entre o tempo de ciclo e a queda de temperatura do aço líquido na panela.

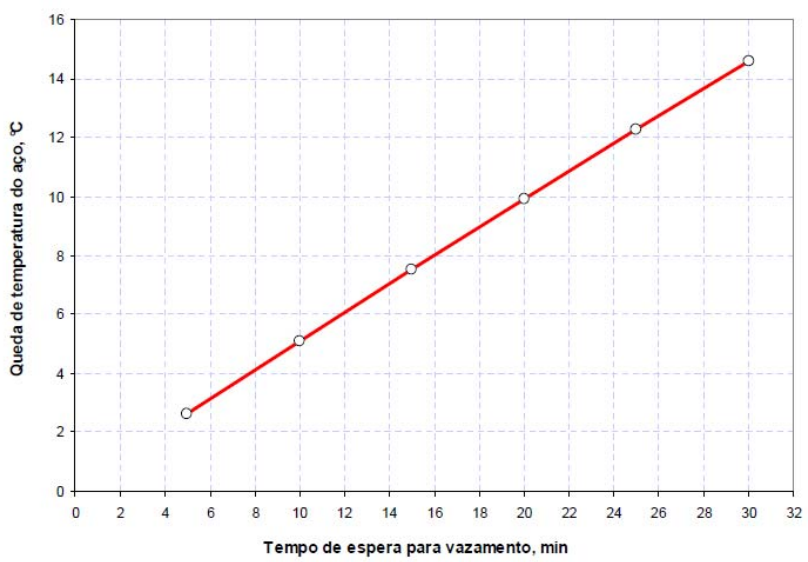

Figura 2. Influência do tempo de ciclo na perda térmica do aço líquido [5]

Da mesma forma, a condição térmica do distribuidor influencia na queda de temperatura (perda térmica) do aço líquido. O preaquecimento do distribuidor e do conjunto de válvulas refratárias é fundamental, pois, além de evitar o choque térmico, deve evitar a solidificação prematura do aço sobre as paredes refratárias das válvulas, o que causa a interrupção da passagem do aço líquido do distribuidor para o molde, e que caracteriza a obstrução. A Figura 3 representa a influência da curva de aquecimento durante o preaquecimento do conjunto de válvulas do distribuidor sobre a temperatura final do canal refratário [5].
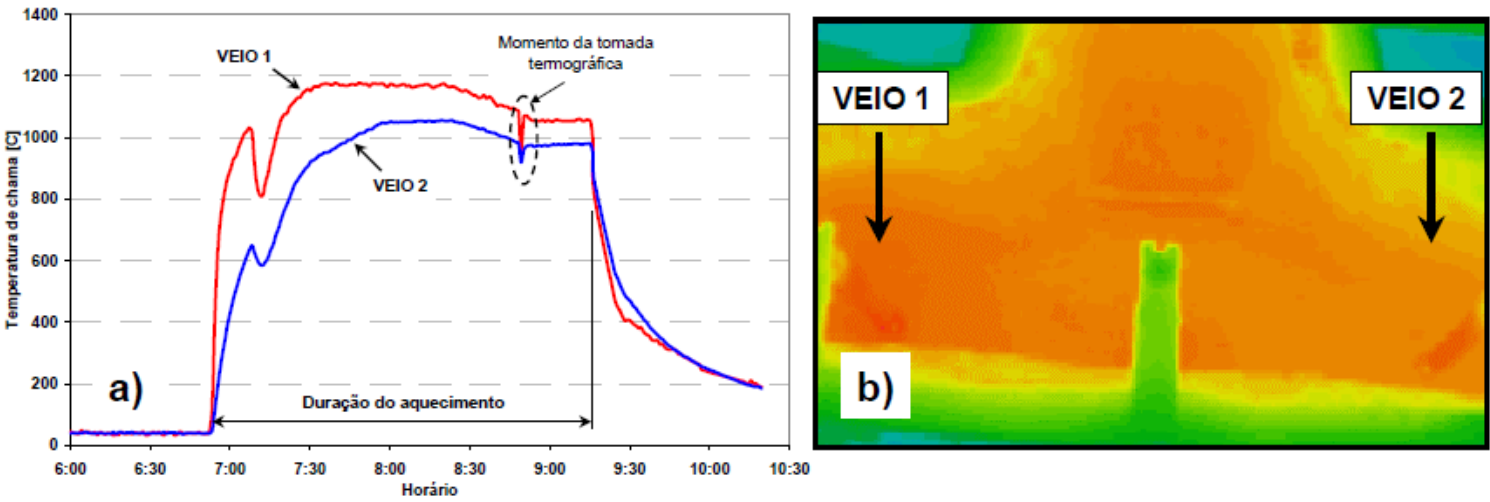

Figura 3. Influência da curva de aquecimento (temperatura de chama) sobre o perfil termográfico na região das válvulas refratárias do distribuidor [5].

O controle da perda térmica do aço líquido no lingotamento contínuo envolve o conhecimento das trocas térmicas tanto no distribuidor quanto na panela de aço, conforme citado acima.

Este trabalho visa o desenvolvimento de um modelo de predição tendo como base o perfil de queda de temperatura do aço líquido no distribuidor. Dessa forma, todas as variáveis do balanço térmico são consideradas sem, contudo, determinar a natureza ou origem da perda térmica associada. 


\section{MATERIAIS E MÉTODOS}

\subsection{Medição Contínua de Temperatura no Distribuidor}

Existem vários métodos de medição da temperatura do aço no distribuidor, onde os principais são mostrados na Figura 4. O mais comum é realizado através da imersão de um sensor termopar no aço líquido, que retorna um valor único de temperatura correspondente à temperatura do aço no momento da imersão. Este método tem o menor custo, mas realiza medições pontuais que não acusam variações da temperatura do aço ao longo do lingotamento. Além disso, a imersão é realizada por um operador, expondo-o ao calor e aumentando o seu tempo de permanência na plataforma da panela [6].

A ArcelorMittal Tubarão implantou um sistema de medição contínua de temperatura em suas máquinas de lingotamento contínuo. Este sistema permite que se tenham medições contínuas de temperatura e também o registro histórico de seu comportamento corrida a corrida, ao contrário da medição discreta/ ou pontual, que permite apenas um número limitado de medições por corrida, conforme ilustrado na Figura 4.

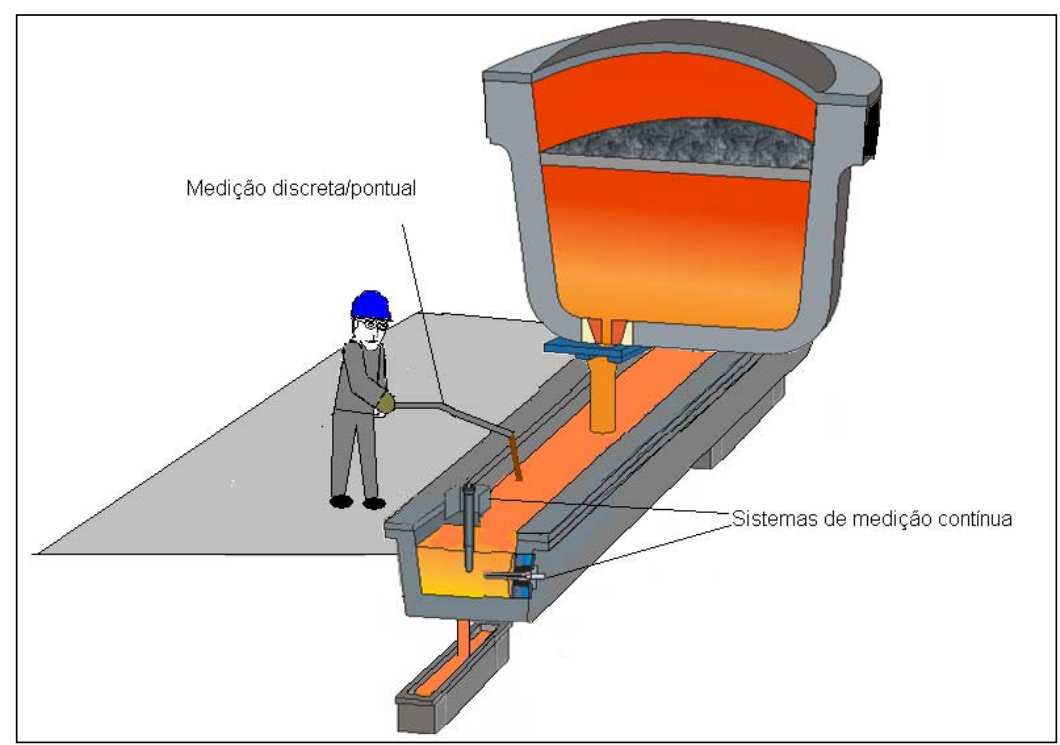

Figura 4. Tipos comuns de medição de temperatura do aço no distribuidor.

A partir do registro contínuo de temperaturas, é possível observar padrões de queda de temperatura do aço no distribuidor em diversas condições de processo, como em tempo longos de lingotamento, em diferentes tipos de aço, entre diferentes condições de panela, etc.

\subsection{Análise das Obstruções por baixa temperatura ocorridas no processo}

Em várias ocasiões foram observadas quedas acentuadas da temperatura ao final do lingotamento de uma panela de aço. Algumas vezes, estas quedas comprometeram a continuidade da sequencia, uma vez que foram observadas ocorrências de obstrução das válvulas por baixa temperatura.

No exemplo que se segue foi observada obstrução no veio 4 da Máquina de Lingotamento Contínuo \#2 da AM Tubarão, na $6^{a}$ corrida do distribuidor, em um aço baixo carbono, que resultou em retorno de 11,0 t no distribuidor. O lingotamento foi normal até a $5^{\mathrm{a}}$ corrida, sem sinais de obstrução nas válvulas. Nesta corrida houve 
grande queda de temperatura no seu final, com o superaquecimento se situando entre 7 e $8^{\circ} \mathrm{C}$. As válvulas submersas saíram limpas, o que leva a supor que a obstrução ocorreu devido à formação de cascão de aço na válvula superior.

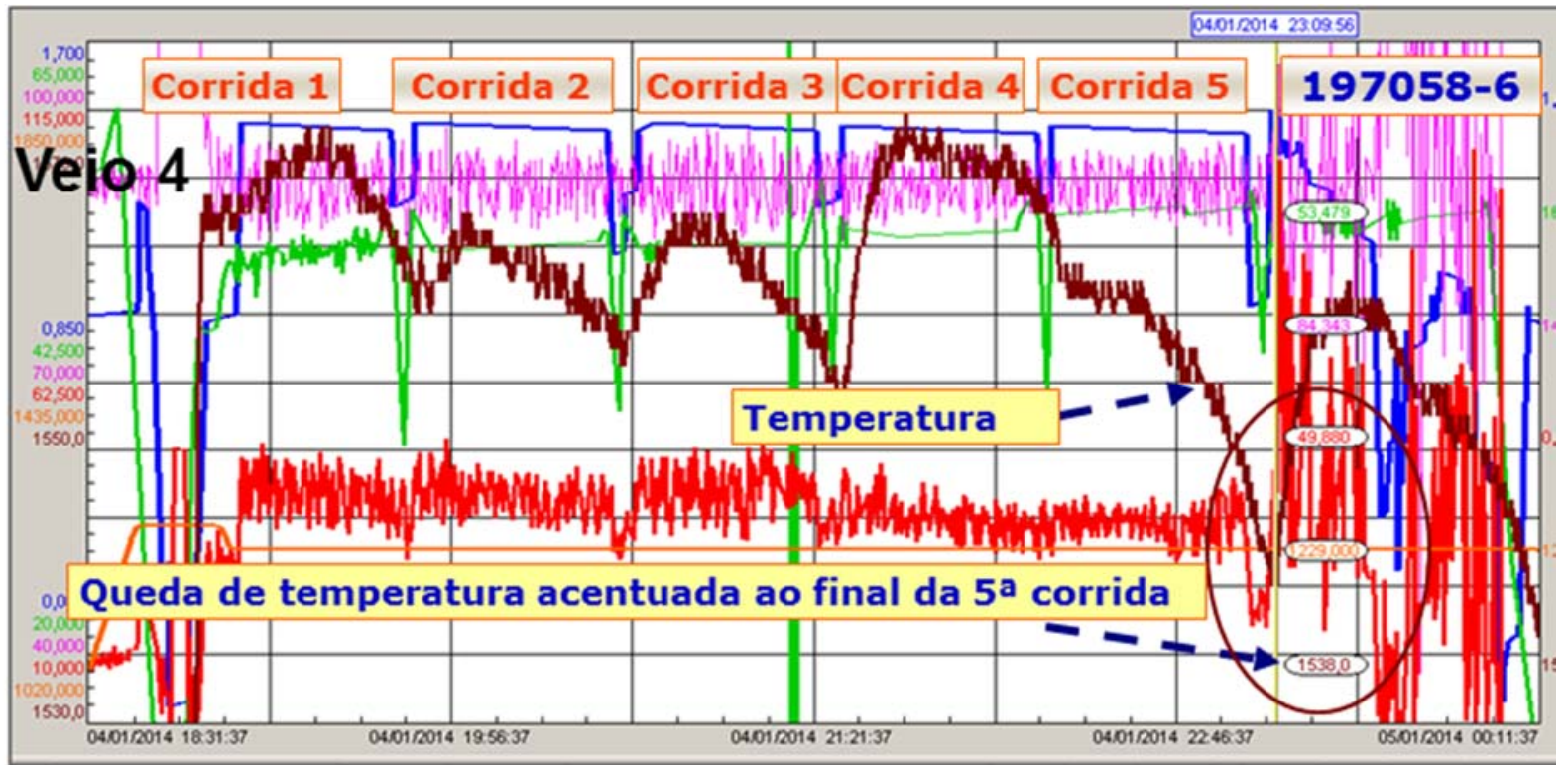

Figura 5. Registro de Ocorrência de queda de temperatura na MLC\#2 da AM Tubarão.

Uma das evidências de que provavelmente ocorreu obstrução por cascão de aço pode ser observada na Figura 6, que mostra a placa superior, lado inferior do K-7 de um sistema de placas deslizantes utilizado para controle de fluxo de aço líquido na MLC2. O veio onde ocorreu a obstrução não apresentou nenhum sinal de arraste de ar e também não mostra formação de alumina nesta placa. Caso a obstrução tivesse ocorrido devido à alumina na válvula superior, haveria cascão na parte superior da placa superior. Portanto, a obstrução deve ter ocorrido devido à formação de cascão sobre a válvula superior por queda da temperatura do aço.

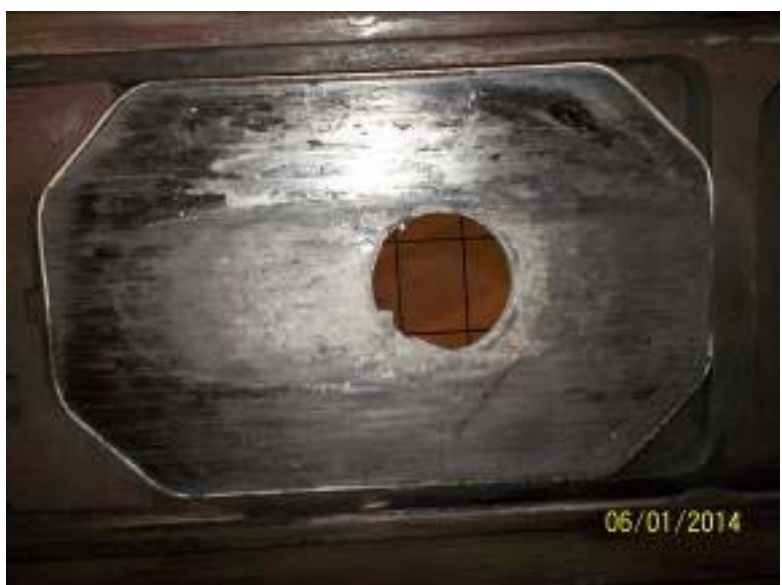

Figura 6. Aspecto da placa deslizante após ocorrência de obstrução por baixa temperatura.

Assim como no exemplo acima, por diversas ocasiões as sequências foram interrompidas em outras máquinas de lingotamento contínuo, e em outras condições de processo, mas com a mesma tendência observada de queda de temperatura ao final do lingotamento de uma panela. 


\subsection{Modelagem do processo}

Para abordar o problema da queda repentina de temperatura do aço no distribuidor através da tomada de decisão (operacional), incorporou-se ao computador de processo do Lingotamento Contínuo 3 da ArcelorMittal Tubarão, um modelo matemático para predição do valor de temperatura no momento do fechamento de panela.

Uma vez que a predição será usada diariamente pela operação do lingotamento contínuo para tomada de decisão, ela deve atender aos seguintes requisitos: (a) o valor previsto deve ser calculado rapidamente, sem comprometer o desempenho do sistema (b) deve ser precisa em apontar os casos de real necessidade de tomada de decisão (c) deve ser ajustada facilmente pelos especialistas de processo por meio de uma interface gráfica.

Para que o modelo fosse incorporado de forma definitiva ao sistema do computador de processo, primeiramente foram realizadas simulações em ambiente de desenvolvimento com dados reais de processo e posteriormente implantado em ambiente de produção em fase experimental.

Como forma de monitorar (avaliar a qualidade) do modelo a cada estimação e, consequentemente, garantir o proposito da correta tomada de decisão, utilizou-se uma medida que quantifica quão preciso o modelo descreve a relação da temperatura ao longo do tempo.

\subsubsection{Definição do modelo}

Basicamente, dois tipos de modelos de predição de temperatura poderiam ser desenvolvidos: modelos empíricos ou modelos de regressão e modelos físicos.

Diferentemente dos modelos de regressão, os modelos físicos são definidos através de equações matemáticas que descrevem o processo (fenômeno) de resfriamento do aço, como as perdas de calor por condução e radiação, tanto no distribuidor como na panela de aço.

Apesar dos modelos físicos poderem, em teoria, fornecer uma precisão elevada, este tipo de modelo requer um detalhamento grande dos dados de entrada, que muitas vezes não estão disponíveis, sendo portanto de difícil incorporação ao computador de processo.

Por outro lado, modelos de regressão empíricos são, em muitos casos, mais fáceis de desenvolver e validar. Adicionalmente, modelos de regressão podem fornecer uma estimação de incerteza necessária associada a um nível de confiabilidade do modelo [7].

\subsubsection{Modelo de regressão linear}

Neste trabalho optou-se pelo modelo de regressão linear. O principal objetivo da regressão linear é ajustar uma linha reta a um conjunto de dados de modo que $Y$ (variável resposta) possa ser previsto em função de $X$ (variável observada).

Uma das formas de se determinar a reta é o método dos mínimos quadrados, onde o ajuste das retas consiste em minimizar o erro quadrático médio das medidas. Este método consiste em calcular o coeficiente angular a e o coeficiente linear $b$ da equação da reta $y=a \cdot x+b$ [8].

No presente trabalho, $x$ será o instante da medição de temperatura, e y será o próprio valor da medição de temperatura do distribuidor. 


\subsubsection{Comportamento linear da temperatura}

Conforme pode ser observado na Figura 7, a variação da temperatura do aço no distribuidor ao longo de uma corrida não pode ser representada por uma equação linear, sendo difícil neste caso a definição de uma equação única que descreva a relação entre temperatura e tempo.

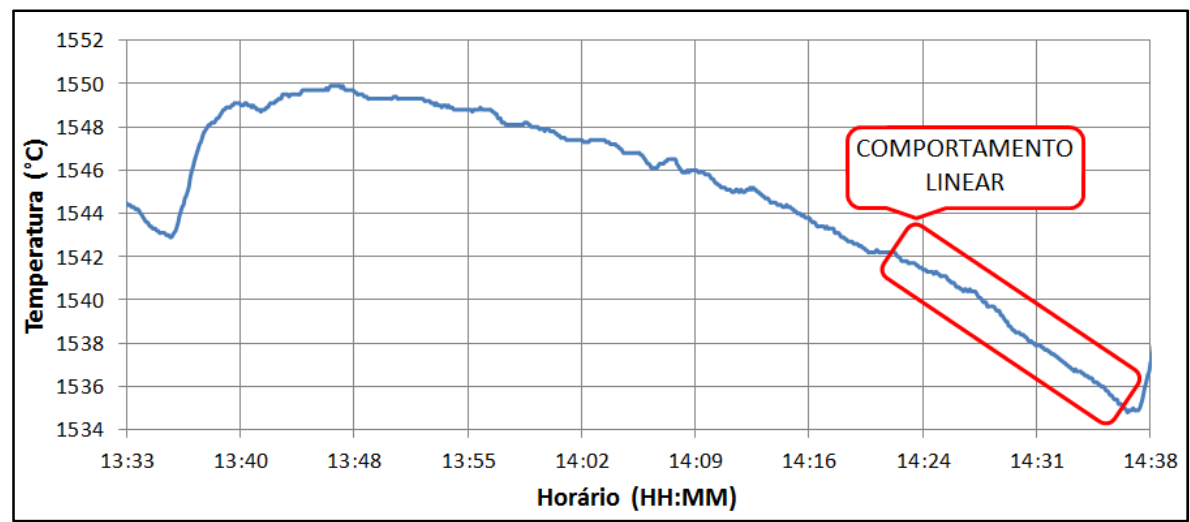

Figura 7. Temperatura do aço no distribuidor ao longo de uma corrida

Entretanto, observou-se que à medida que as medições de temperatura aproximamse do horário de fechamento de panela, os segmentos de curva próximos a esse horário podem ser aproximados a segmentos de reta, ou seja, as medições de temperatura ao longo do tempo tem uma concordância muito aproximada com uma reta, conforme ilustra a Figura 8.

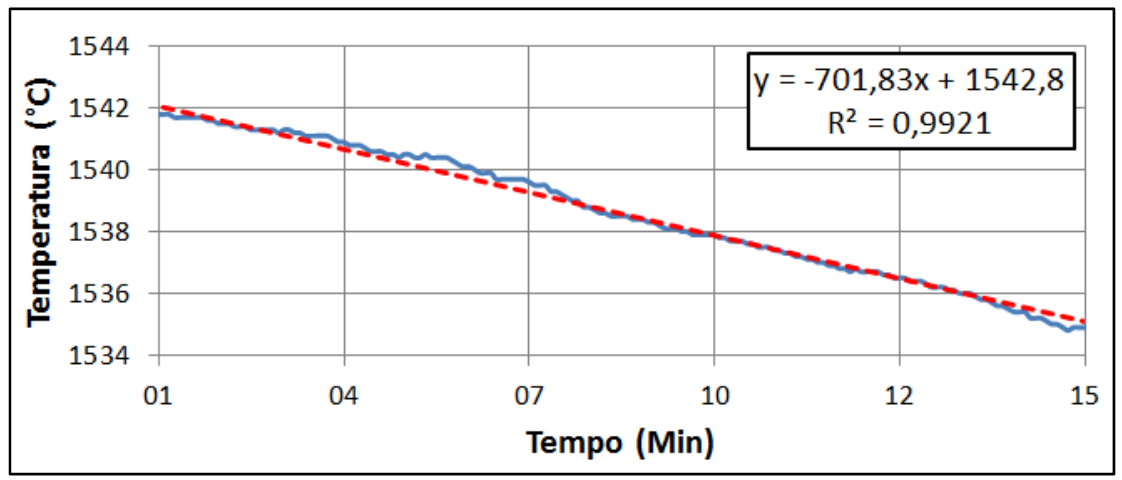

Figura 8. Aproximação linear da temperatura ao final de uma corrida.

\subsubsection{Qualidade do modelo}

Como forma de avaliar a qualidade do modelo em relação a sua habilidade de estimar corretamente os valores da temperatura ao final da corrida, ou seja, quão preciso o modelo pode ser em relação ao ajuste das amostras, considerou-se uma amostragem de 37 corridas.

Conforme pode ser observado na Figura 9, o coeficiente de correlação de Pearson esteve majoritariamente acima de 0,9 , indicando uma correlação muito forte entre a temperatura e o tempo. Desse modo, conclui-se que a temperatura pode ser prevista com certo grau de certeza em função do tempo [7]. 


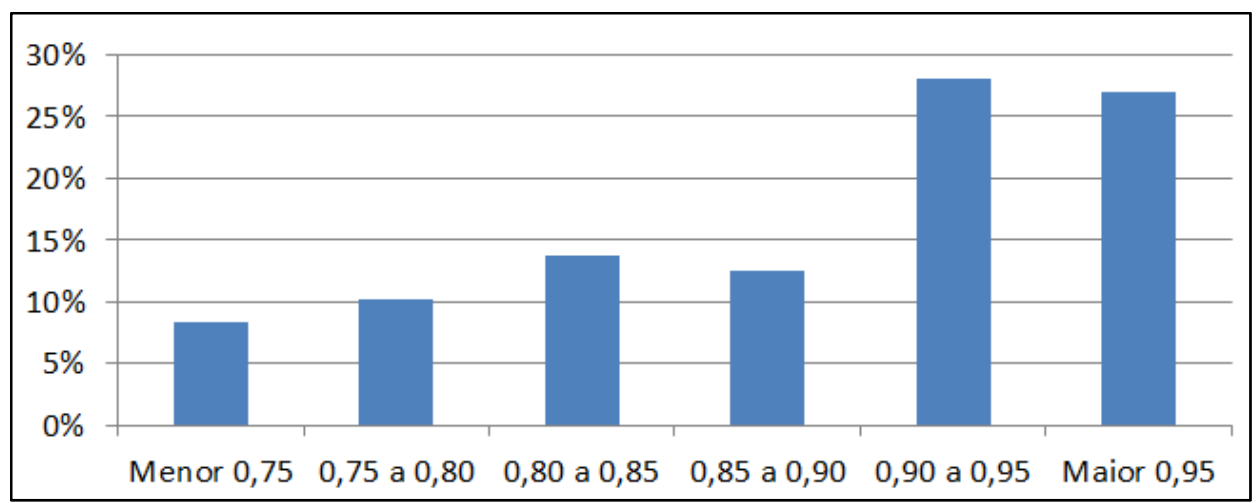

Figura 9. Histograma de distribuição dos coeficientes de correlação (37 corridas).

\section{RESULTADOS E DISCUSSÃO}

\subsection{Resultados de validação do modelo}

O modelo foi validado comparando-se as observações das temperaturas de final de panela com os valores previstos para o mesmo momento. Conforme ilustra a Figura 10, observa-se que a estimativa ao longo de 10 minutos manteve-se próxima da temperatura final, onde o erro manteve-se inferior a $1,5 \mathrm{C}^{\circ}$, conforme a Figura 11.

Para efeito de tomada de decisão, quanto antes a condição de baixa temperatura for detectada, mais tempo a operação disporá para tomada de decisão.

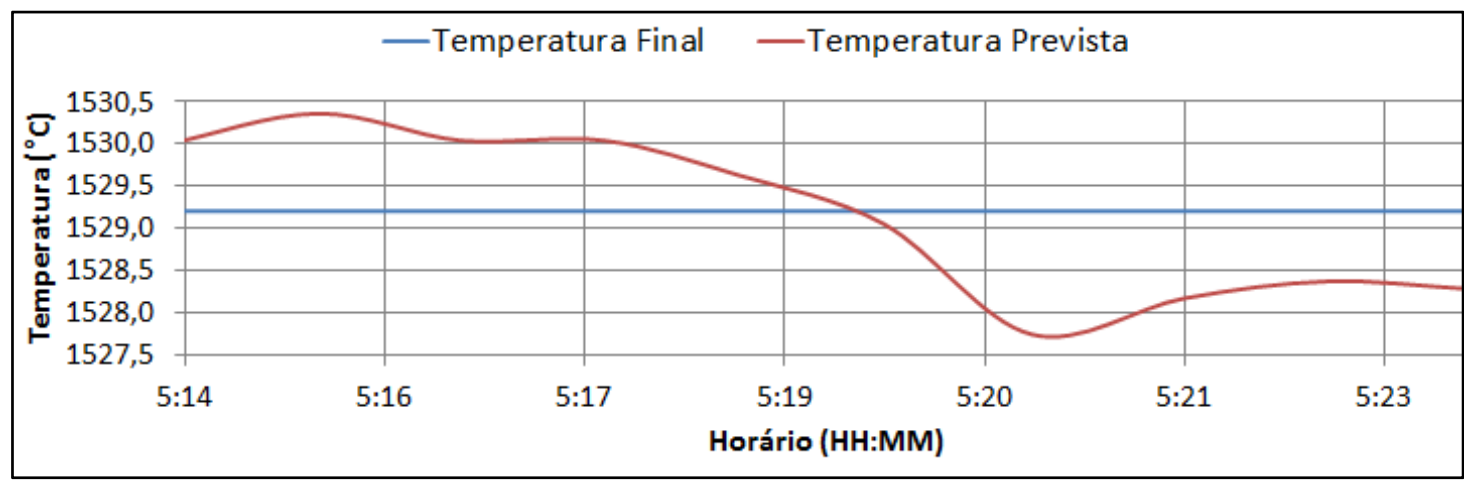

Figura 10. Estimativa do modelo ao longo de 10 minutos no encerramento de uma panela.

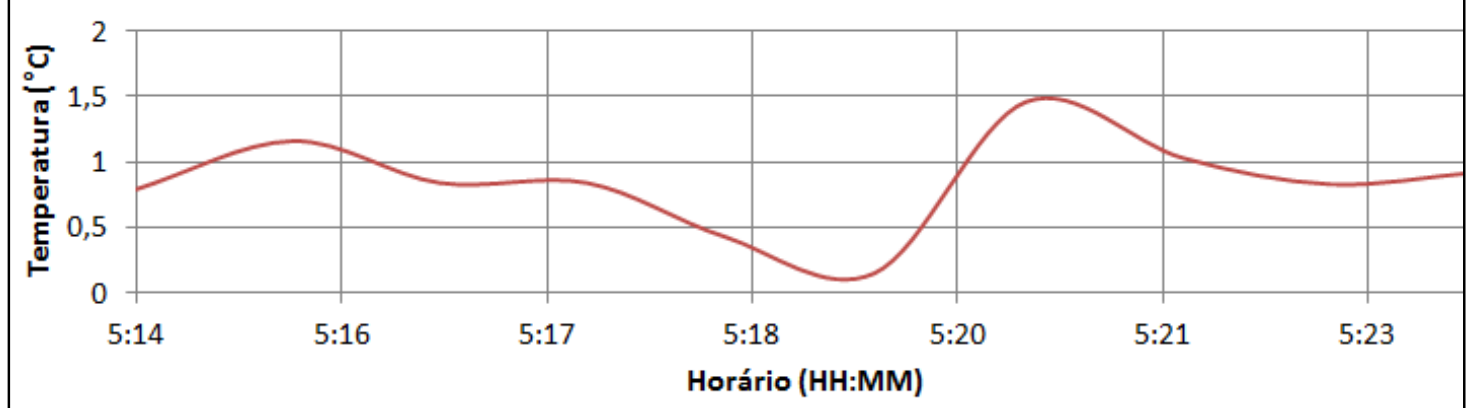

Figura 11. Erro de predição estimado pelo modelo no encerramento de panela.

\subsection{Implantação do Modelo na Área Operacional}

O modelo se encontra em fase de implantação na Máquina de Lingotamento Contínuo número 3 da ArcelorMittal Tubarão. No momento ele ainda não gera alarmes para o operador, mas registra on line todas as ocorrências potenciais de 
queda de temperatura e da taxa desta queda, e que poderiam conduzir a um eventual congelamento do aço e consequente interrupção do lingotamento.

Desta forma, será possível identificar o melhor tempo de início de geração dos alarmes, que será em função da frequência de ocorrência e da criticidade observada após o mesmo. Será observado se o evento parou de fato a máquina, ou se gerou obstrução com consequências para a qualidade, ou mesmo outros critérios, levando sempre em conta o risco de uma decisão que vai impactar também no rendimento, caso se antecipe uma troca de panela, ou mesmo na interrupção temporária da produção (com risco de retorno de panela, redução de sequencial de distribuidor e outros efeitos).

\section{CONCLUSÃO}

Foi proposto o desenvolvimento de um modelo de predição de queda de temperatura ao final do lingotamento de uma panela no lingotamento contínuo da ArcelorMittal Tubarão;

O modelo utiliza dados da medição contínua de temperatura, com os quais é possível estimar, através de regressão linear, e com razoável nível de certeza, o valor final da temperatura do aço no distribuidor, quando do encerramento da panela;

Os erros associados à predição se mostraram em níveis aceitáveis, mantendo-se inferiores a $1,5^{\circ} \mathrm{C}$ nas ocorrências observadas;

O modelo encontra-se em fase de testes na máquina de lingotamento contínuo número 3 da ArcelorMittal Tubarão, com o intuito de gerar um número de dados necessários para o estabelecimento dos limites de tempo e de taxa de queda de temperatura para a geração dos alarmes;

Este modelo visa dar subsídios para a decisão de interrupção de lingotamento, ou antecipação de abertura de panela, evitando os transtornos associados à ocorrência de obstrução do lingotamento por baixa temperatura.

\section{REFERÊNCIAS}

1 Perim CA, Barbosa, FA, Henriques, BR, Kaushiki, P. Aumento do sequencial de distribuidor em aços ultra baixo carbono estabilizados ao titânio na ArcelorMittal Aços Planos América do Sul. $46^{\circ}$ Seminário de Aciaria - Internacional, ABM Week, Agosto de 2015, Rio de Janeiro/ RJ, Brasil.

2 Rackers, K., and B.G. Thomas. Clogging in Continuous Casting Nozzles. 78th Steelmaking Conference Proceedings, Nashville, TN, April 2, 1995, Iron and Steel Society, Warrendale, PA, Vol. 78, 1995, pp. 723-734

3 Ferreira NF, Henriques BR, Severo DS. O modelo matemático das panelas da CST. XXXIII Seminário de Fusão, Refino e Solidificação dos Metais - Santos/SP, Brasil. Maio de 2002.

4 Carvalho MC, Oliveira DR, Rusky GC, Pinheiro BC, Souza JAS, Braga EM. Simulação Computacional das Panelas de Aciaria da Siderúrgica Sinobras S.A. Tecnologia em Metalurgia, Materiais e Mineração. 2014;11(2):138-145

5 Lopes HLP. Modelo para previsão da condição térmica de panelas de aciaria [dissertação de mestrado]. Belo Horizonte: Universidade Federal de Minas Gerais; 2007.

6 Fialho, MM et al. Medição contínua de temperatura do aço no distribuidor: Utilização do sistema Castemp na ArcelorMittal Tubarão. $43^{\circ}$ Seminário de Aciaria Internacional da ABM, Belo Horizonte, Maio de 2012. 
7 Neumann DW, Rajagopalan B, Zagona EA. 2003. Regression model for daily maximum stream temperature. Journal of Environmental Engineering 129: 667-674.

8 Zou KH, Tuncali K, Silverman SG. Correlation and simple linear regression. Radiology. 2003 Jun; 227(3):617-22. 